\title{
A Filosofia Moderna em Quadrinhos
}

Modern Philosophy Comics

Gabriel Kafure da Rocha (Org.) ${ }^{1}$

Eliana Passos Silva de Oliveira

Elton Silva de Oliveira

Estela Araújo Silva

Francoilia Rodrigues Soares

Jaqueline Caren da Silva Santana

Joana Darc Aguiar dos Santos

Joelma da Silva Simões

Katússia Benedita dos Santos de Almeida

Marilene Evangelista da Silva

Regiane Rocha Oliveira

Sanoraide do Nascimento Santos

Taciana Roberta Correia de Alencar

RESUMO: O presente experimento consistiu em uma atividade do Curso de Licenciatura em Filosofia - CEAD UFPI, do polo de Juazeiro - BA. A proposta era de apresentar imagens que ilustrassem citações dos filósofos que iniciaram a História da Filosofia Moderna. Tivemos como resultado a confecção de cordéis, quadrinhos e outras imagens e manifestações artísticas diversas. Tais registros consistem então em possibilidade de trabalho para os professores da área, que muitas vezes não tem tantos recursos imagéticos para trabalhar com os alunos.

PALAVRAS-CHAVE: Quadrinhos, Descartes, Hobbes, Locke, Hume.

ABSTRACT: This experiment consisted in an activity of Philosophy Course of the CEAD UFPI, in Juazeiro - BA. The proposal was to present images that illustrate quotations from philosophers who started the History of Modern Philosophy. We had resulted in the making of twine, cartoons and other images and different artistic manifestations. Such records then consist of the possibility of work for teachers in the area, who often do not have so many pictorial resources to work with students.

KEYWORDS: Comics, Descartes, Hobbes, Locke, Hume.

\footnotetext{
${ }^{1}$ Organizador, orientador e editor do presente estudo. Prof. do Instituto Federal do Sertão Pernambucano. Doutorando em Filosofia pela UFRN. Mestre em Filosofia pela UFPI.
} 


\section{INTRODUÇÃO}

A relação entre filosofia e imagens que será exposta a seguir, foi um trabalho simples de lápis e cores, pintadas com lápis de cera e retocadas com canetas hidrocores. Após esse processo, a maioria dos desenhos passaram por uma edição de vetorização simples, no sentido de ressaltar e retocar melhor algumas imagens e colocar os balões dos diálogos em letra de forma. Desse modo, será exposto a seguir um processo de desconstrução tanto das imagens como da própria filosofia moderna, de maneira bem humorada e também crítica.

\section{Descartes}

René Descartes foi o fundador da filosofia moderna. $\mathrm{Na}$ busca pelo "verdadeiro conhecimento" o filósofo elaborou um método para atingi-lo. Seu Discurso do método consistiu em uma doutrina com a finalidade de conceituar e descrever a verdade com base em princípios racionais. São quatro regras para alcançar o conhecimento verdadeiro: a eviência, análise, síntese e enumeração.
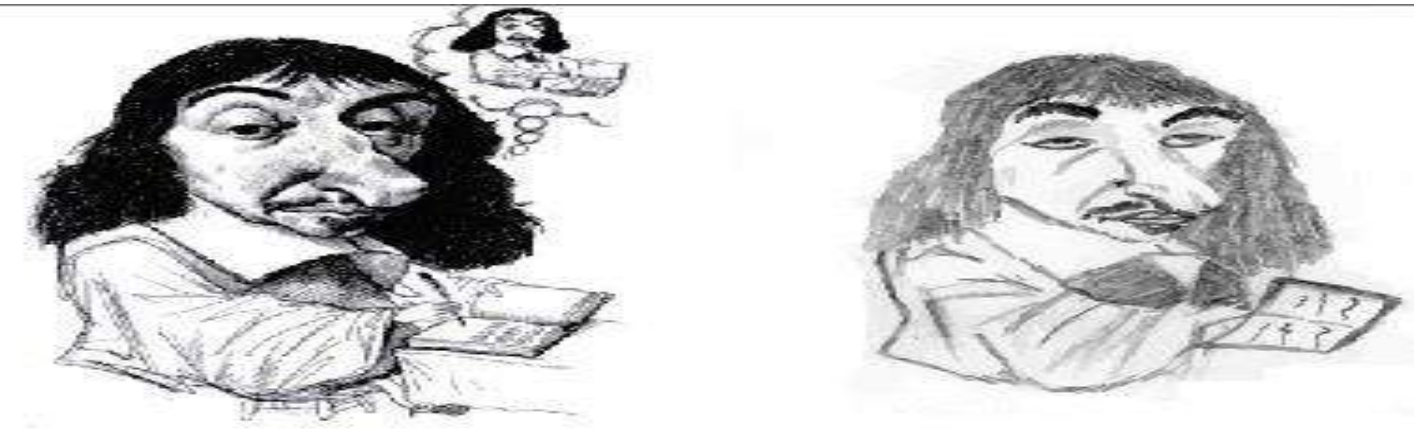

-
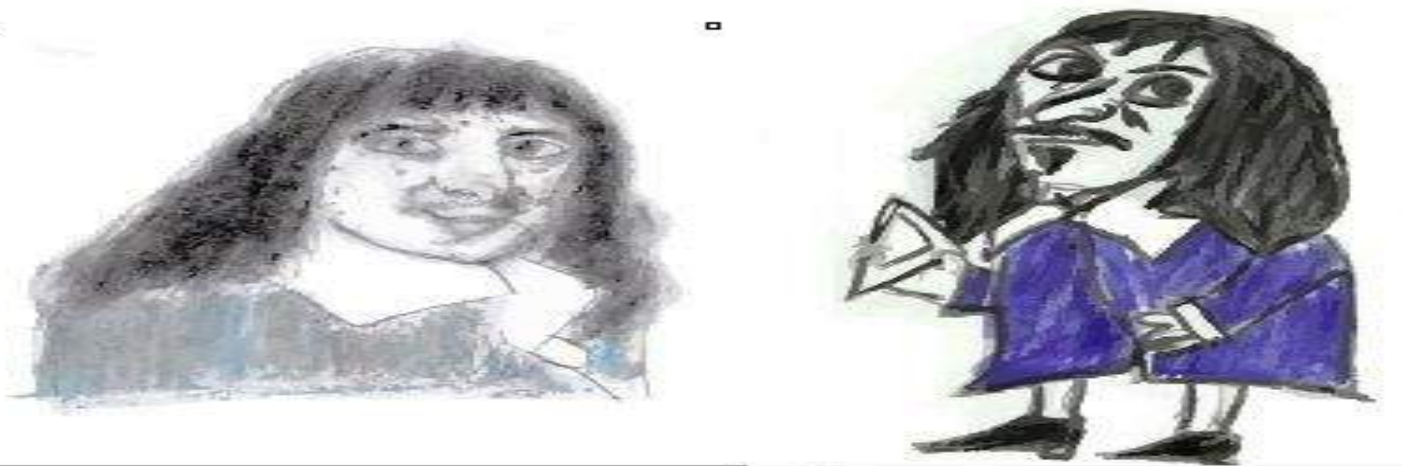

Por Françoilia Soares, Joelma Simões, Jacqueline Caren e Joana Darc (respectivamente da esquerda para a direita) 


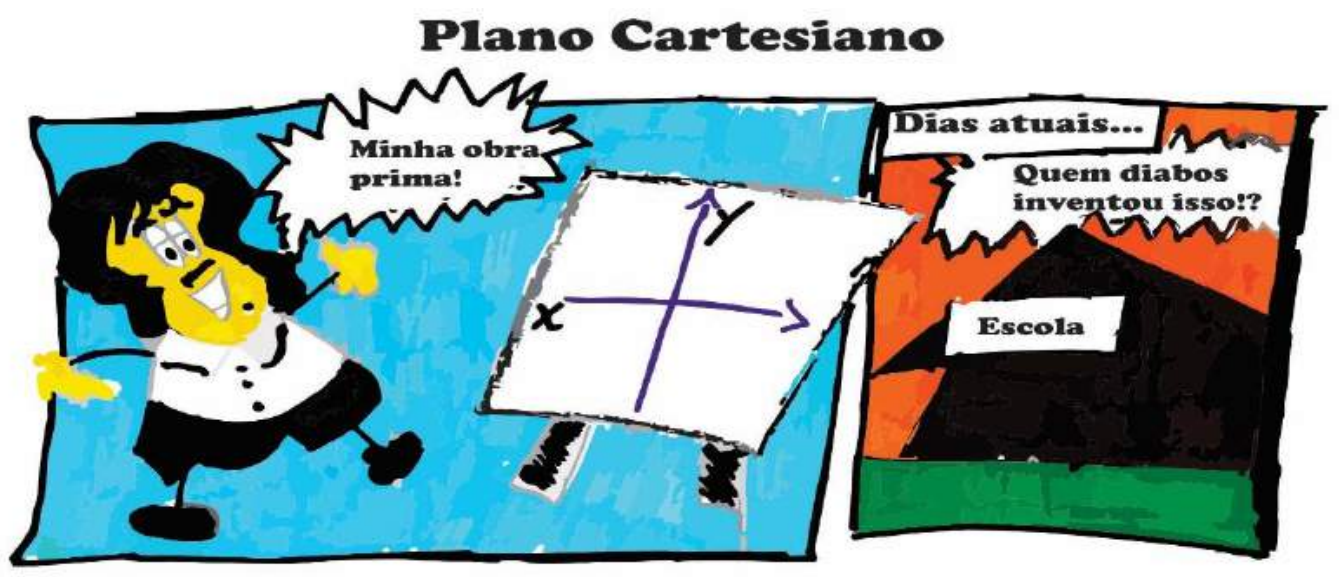

L
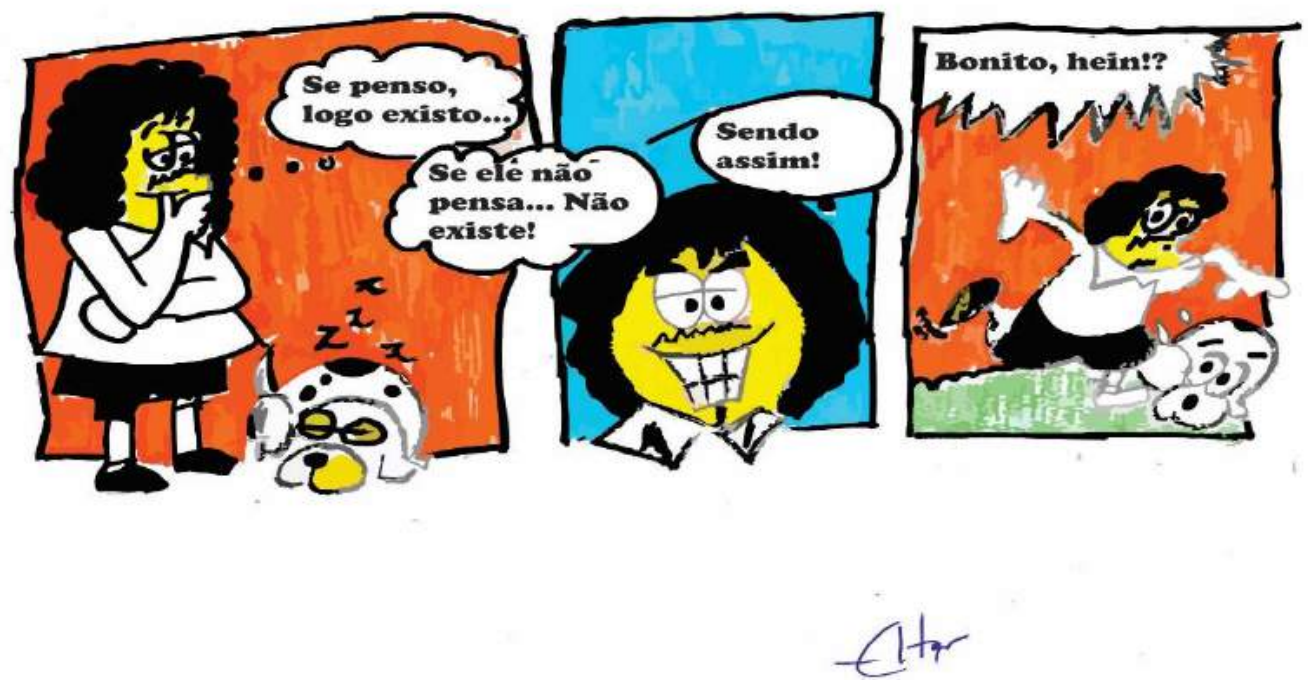

\section{Por Elton Oliveira}

Verificar, analisar, sintetizar e enumerar... Dê ordem ao pensamento. É da natureza da educação a não previsibilidade, não criar o mero mecanismo de controle. Logo, a busca é pelo momento quando a dúvida seja necessária para a descoberta da substância pensante, da realidade do sujeito que pensa. 


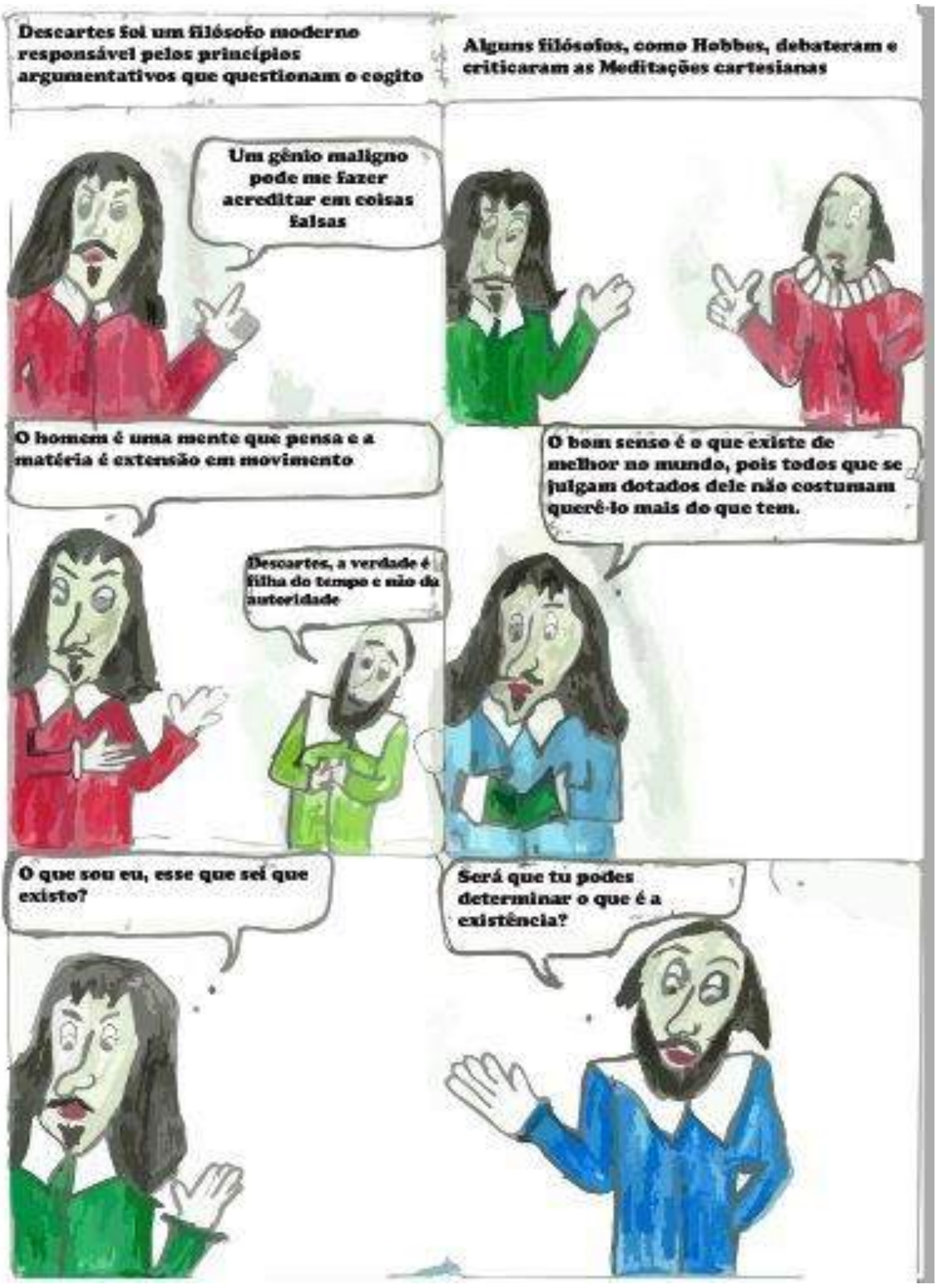




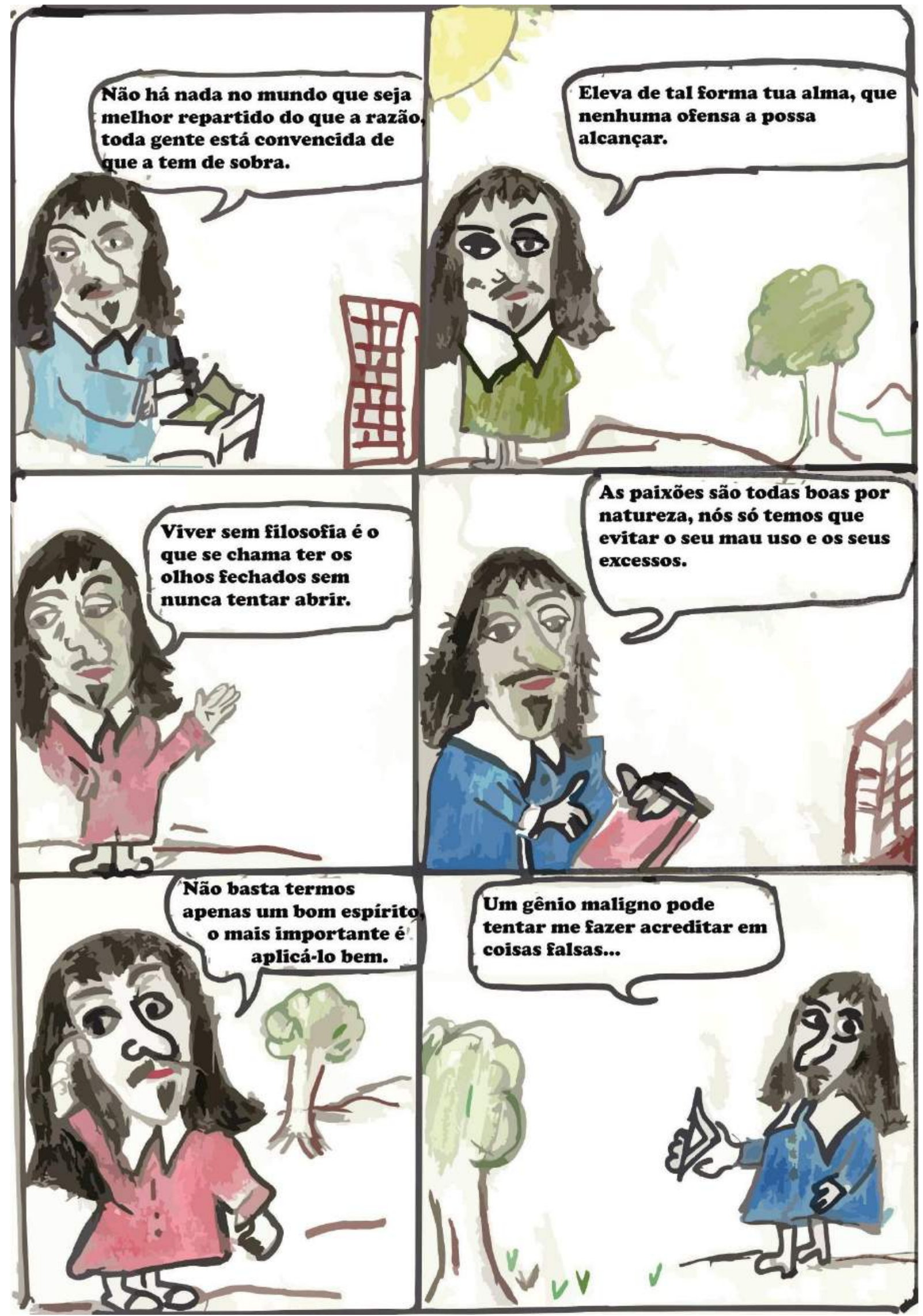




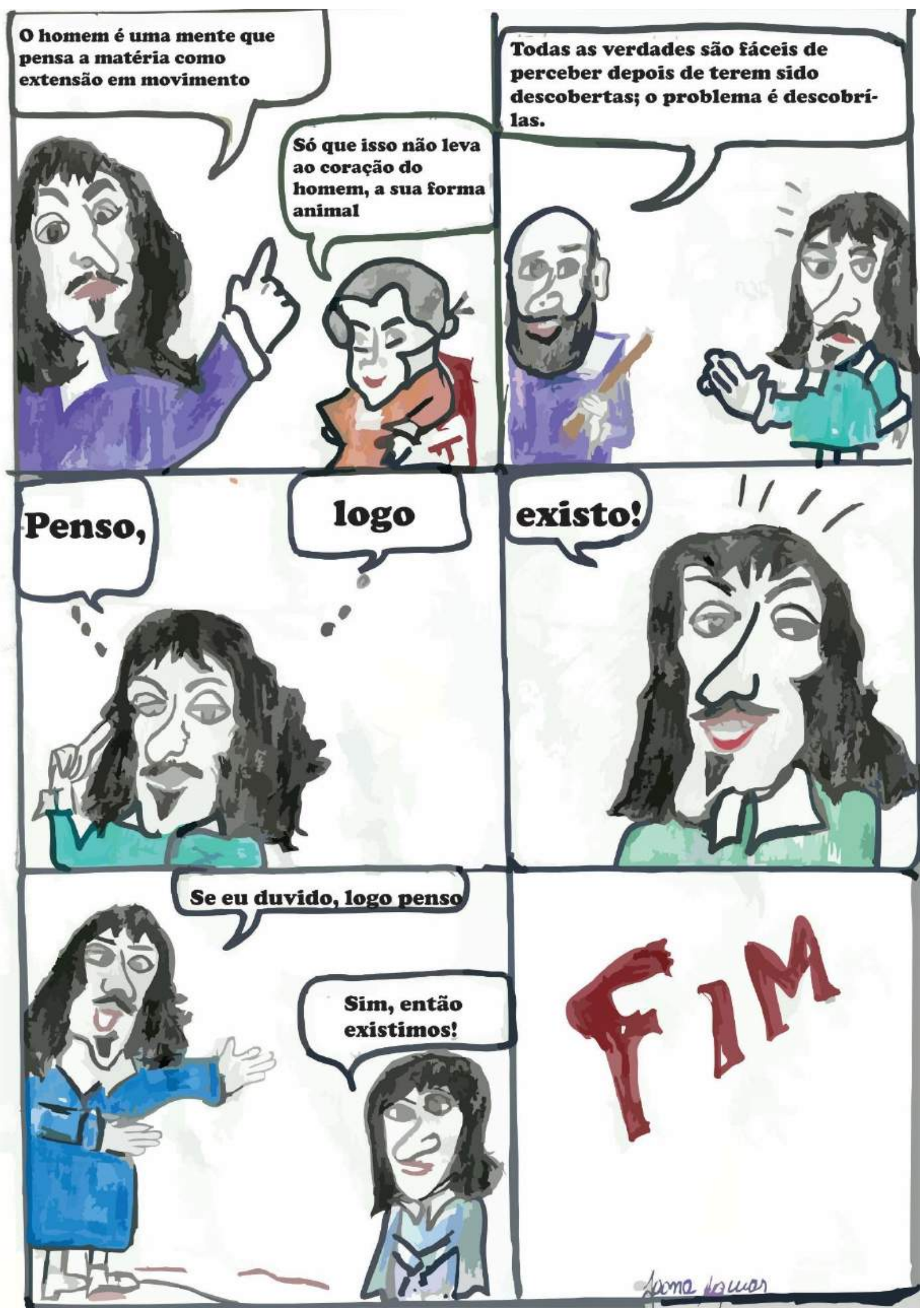




\section{VERDADE INQUESTIONAEVEL}

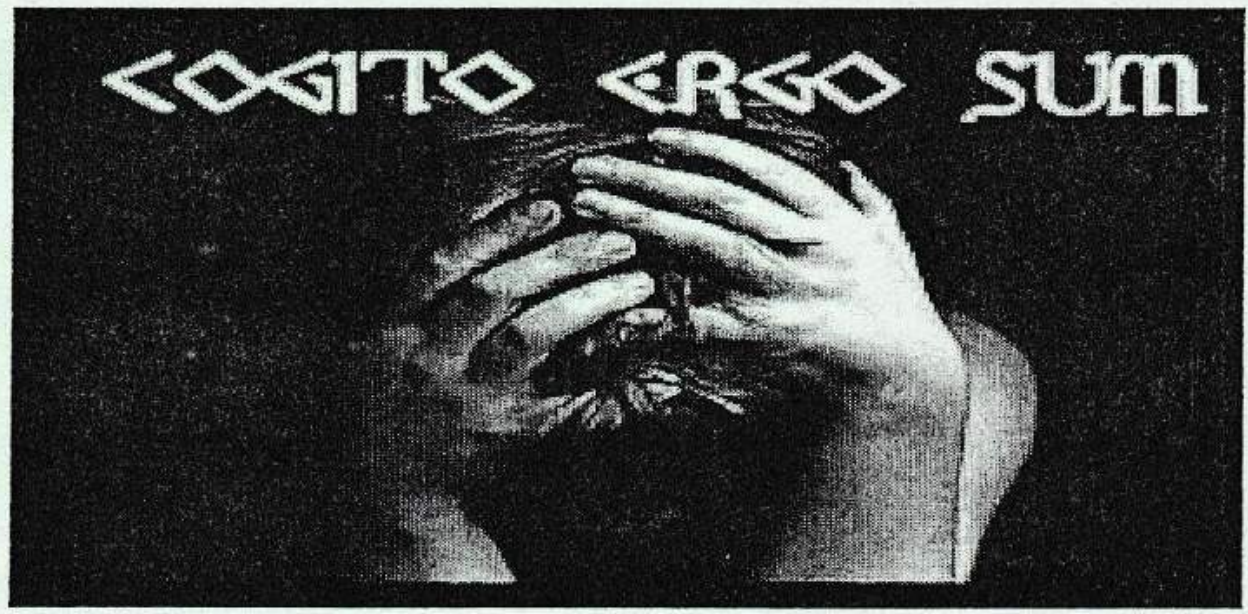

DISCIPLINA: HISTÓRIA DA FILOSOFIA MODERNA

TACIANA ROBERTA CORREIA CORDEIRO DE ALENCAR 2016 


\section{VERDADE INQUESTIONÁVEL}

Duvidar é a missão

Para quem quer respostas,

Questionar com a razão

É a melhor proposta.

Em um mundo de incertezas,

Onde tudo pode não ser,

Ir além de nossos sentidos

É o caminho para o saber.

O mundo sensível é refutável

Os erros são vistos cotidianamente,

E a ciência precisa rever

Seus conceitos diariamente.

A verdade inquestionável

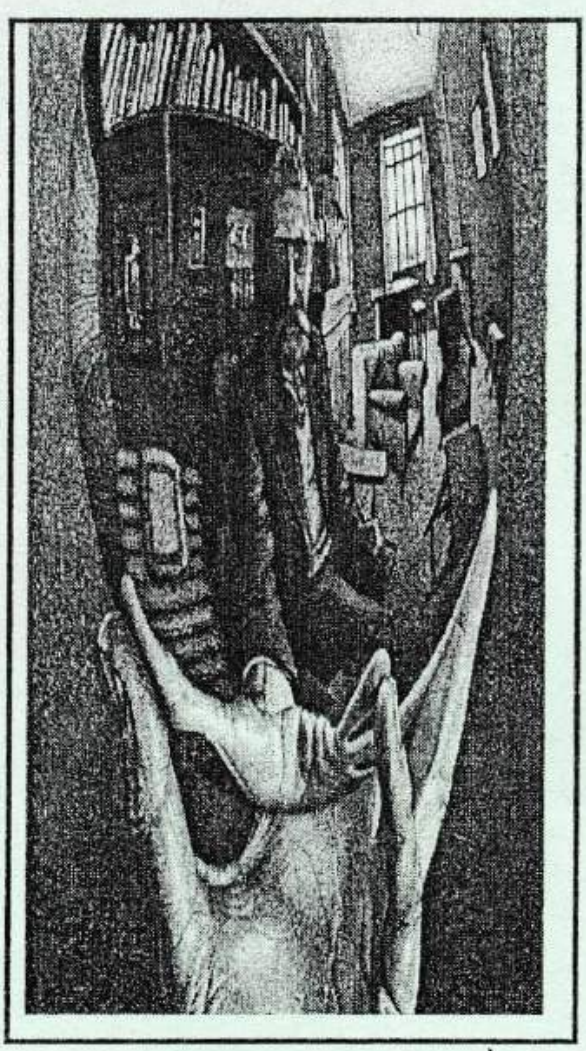

Na dúvida deve começar,

Sentido, memória, ciência,

Tudo é cabível duvidar. 
Daí vem a conclusão

Do que não se pode questionar,

Ao criar a própria dúvida

Temos a certeza do pensar!

Se penso, logo existo,

Essa foi a afirmação

De um filósofo inquieto

Pelo uso da razão.

Mudou a rota do pensamento,

Iniciou boa reflexão,

Renatus Cartesius foi a base

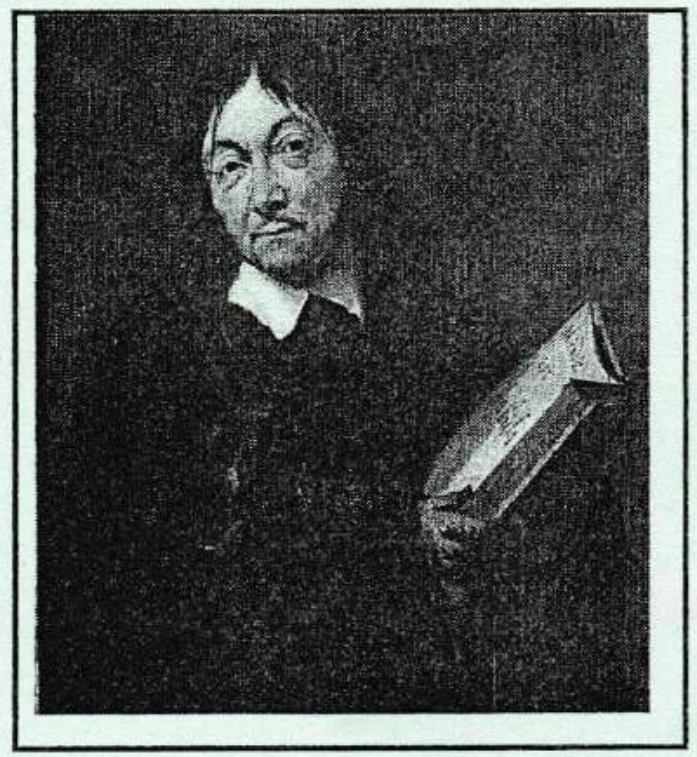

Para uma mudança de concepção.

Se quem duvida pensa,

E quem pensa existe,

A existência não se pode duvidar,

Sendo fato, é preciso comprovar! 
Um dualismo psicofísico

Faz parte desse novo olhar,

Corpo e mente se entrelaçam

Para a verdade constatar.

Uma método foi preciso

Para tudo comprovar,

Era um novo rumo ao conhecimento,

Que à modernidade veio iluminar!

Verificar, analisar, sintetizar e enumerar,

Fazem parte de um processo.

Era a ciência seguindo o norte

Do simples para o complexo.

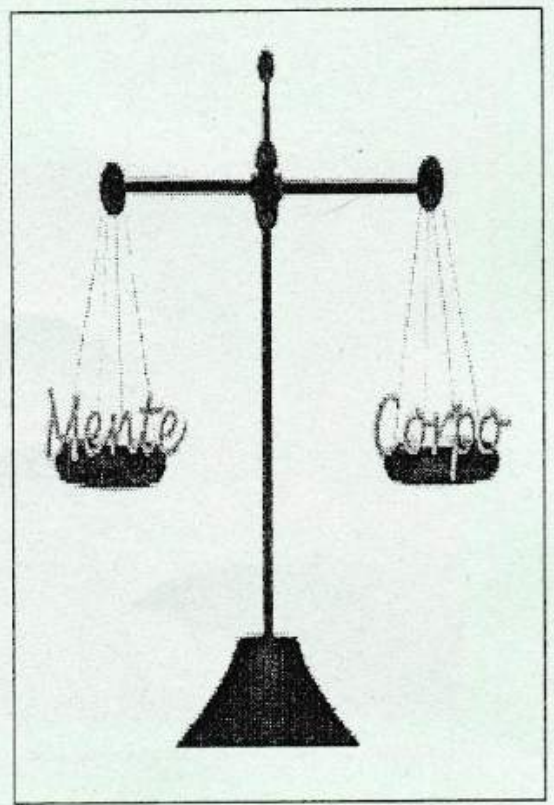

Verificar o que se propõe,

É por onde deve-se começar,

Saber se existem evidências

A cerca do que se vai estudar. 
Analisar exige critérios,

Que não se pode esquecer!

Dividir o problema em partes,

Para melhor compreender.

Sintetizar é imprescindível

Em todo pensar corriqueiro,

Unir todas as partes, criar um todo,

Que seja verdadeiro!

Enumerar os procedimentos,

Catalogar as ordens e conclusões

Para que sirvam de subsídios

Em outras análises e definições.

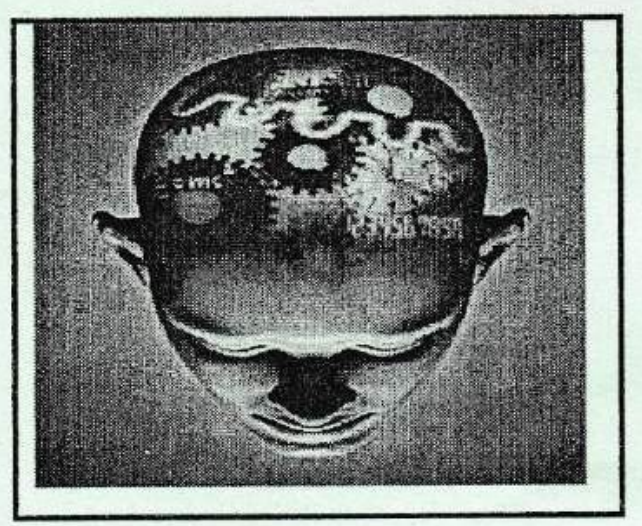

Caminhando para a verdade,

Outra grande contribuição

Foi entender o solipsismo

Como necessário à razão. 
Impossivel conhecer

A essência do outro em questão,

A dualidade com a aparência,

Nem sempre convergem na relação.

Com René Descartes, um novo olhar, Variados foram os encaminhamentos,

Mas a verdade inquestionável é:

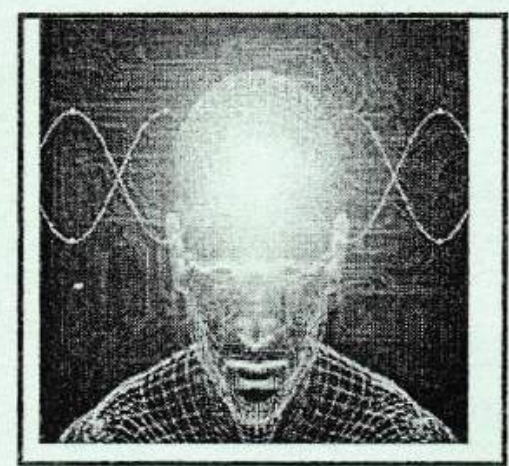

A existência se define pelo pensamento! 


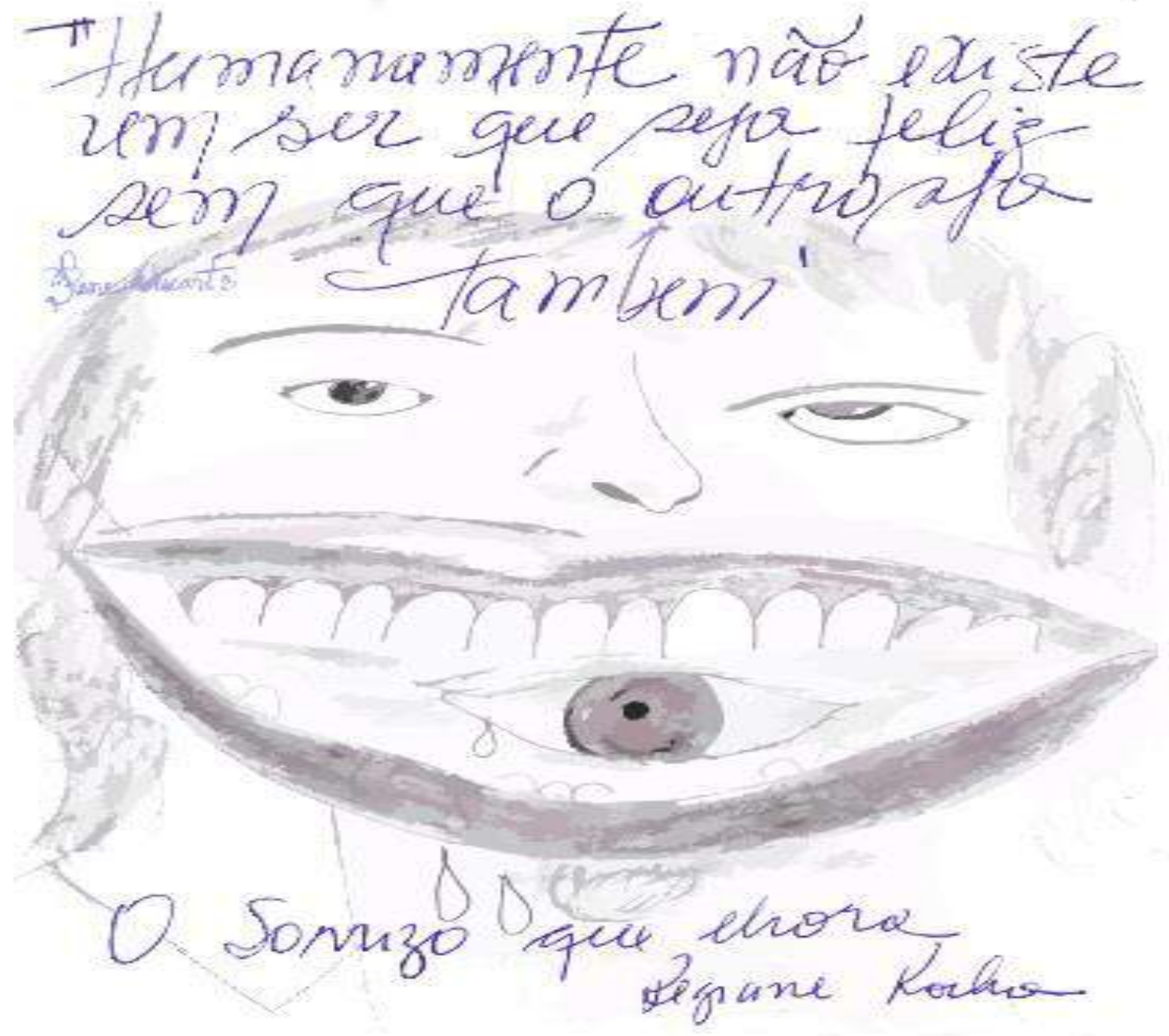

\section{Por Regiane Rocha}

Quem pode ser feliz em meio a tantas dores? [...] Feliz com muito e o outro com nada! Se a partilha fosse mínima, a fome não era semeada. 


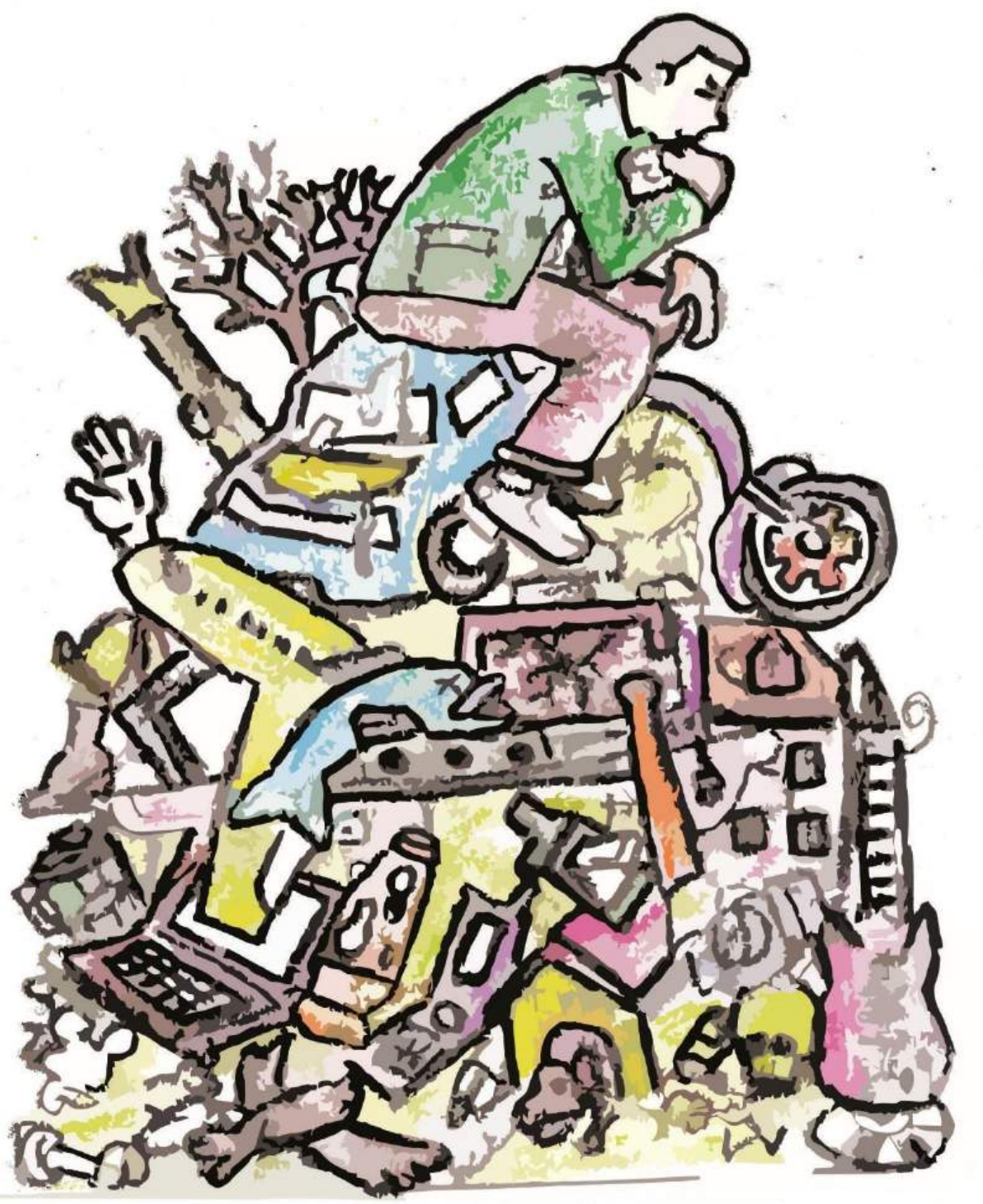

Por Estela Araújo Silva

Em um mundo de tantas incertezas, tão fluído, onde tudo parece desaparecer, o que fica inevitavelmente é a certeza do eu. Duvidar das verdades impostas e dos conhecimentos refutados ou refutáveis, das sensações passíveis de equívocos, faz parte da busca constante que devemos nos propor a fazer para a construção de nós mesmos. 


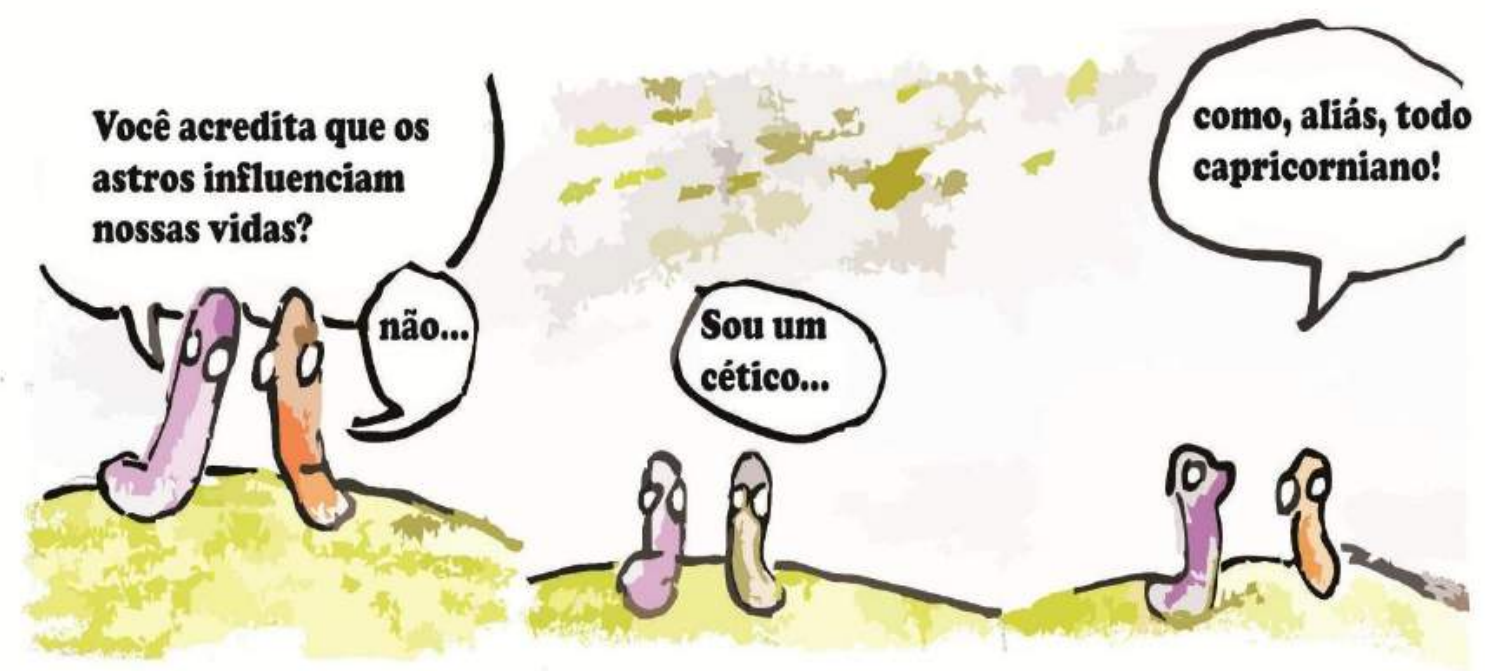

\section{Por Jaqueline Caren Santana}

A dúvida é o contrário da certeza. Duvidar é pensar, mas sem estar seguro da verdade do que se pensa. Os céticos fazem da dúvida o estado último do pensamento. Os dogmáticos, quase sempre, uma não condição prévia. Assim, seja a dúvida metódica ou hiperbólica, ela não seria mais do que um momento provisório da busca pela certeza. Descartes sai dela por meio do cogito, que não é duvidoso, diga o que se disser, nada impede que o cogito também seja enganador. Assim, a dúvida deve renascer sempre, não se sai dela senão pela própria ação de duvidar. 


\section{Hobbes}
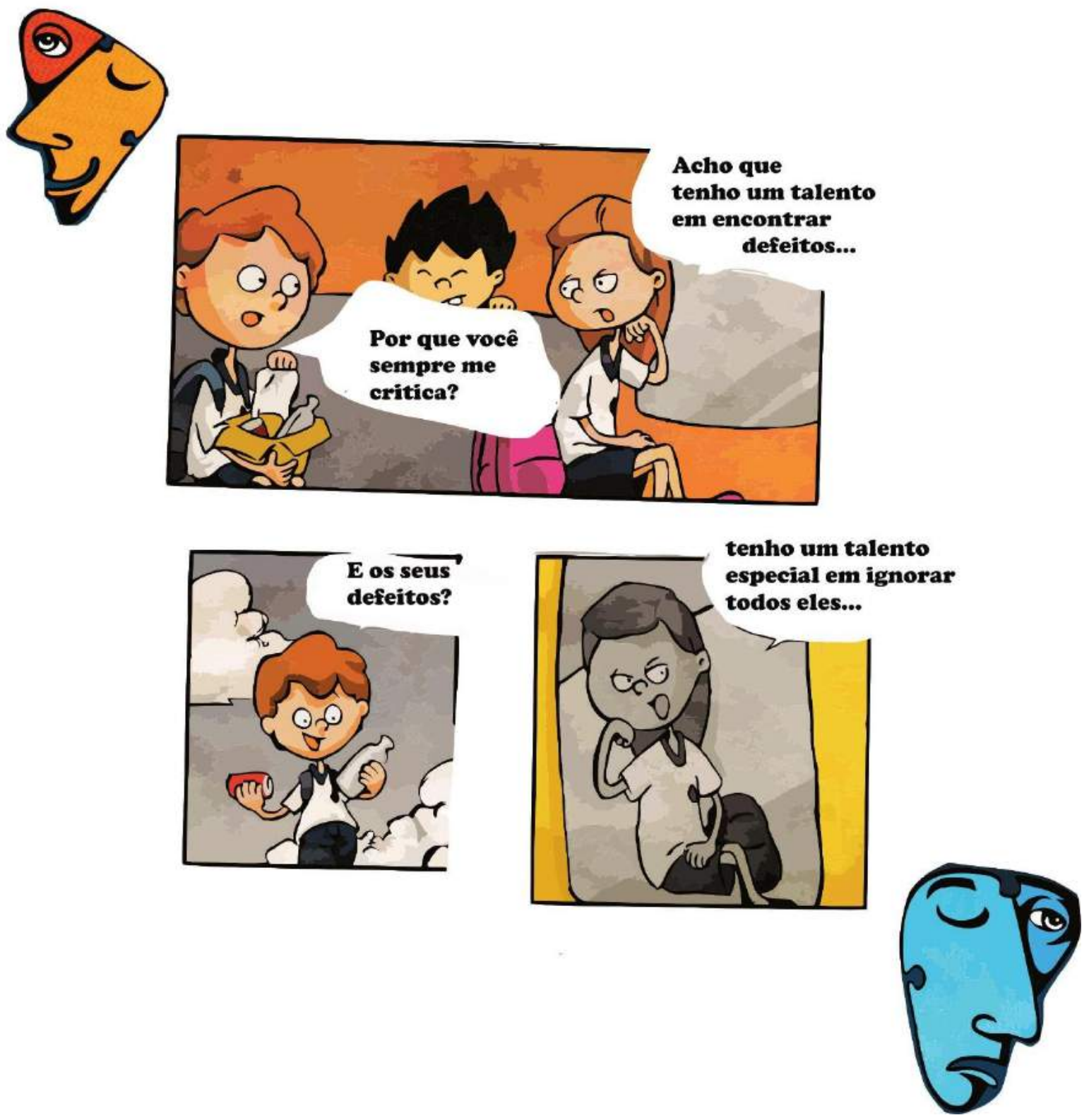

Por Marilene Evangelista da Silva - O paradoxo do Riso

Segundo Hobbes, os homens amam naturalmente a liberdade e o domínio sobre os outros, deleitam-se com os demais a fim de se sentirem superiores. O Filósofo diz que o riso pode mostrar fraqueza, já que o homem ri para se sentir superior, ou seja, porque ele identifica um defeito no outro. Atualmente, existe um paradoxo do riso, que está muito presente em todos os níveis da sociedade, mas há quem diga que rimos cada vez menos. 


\section{Hume}

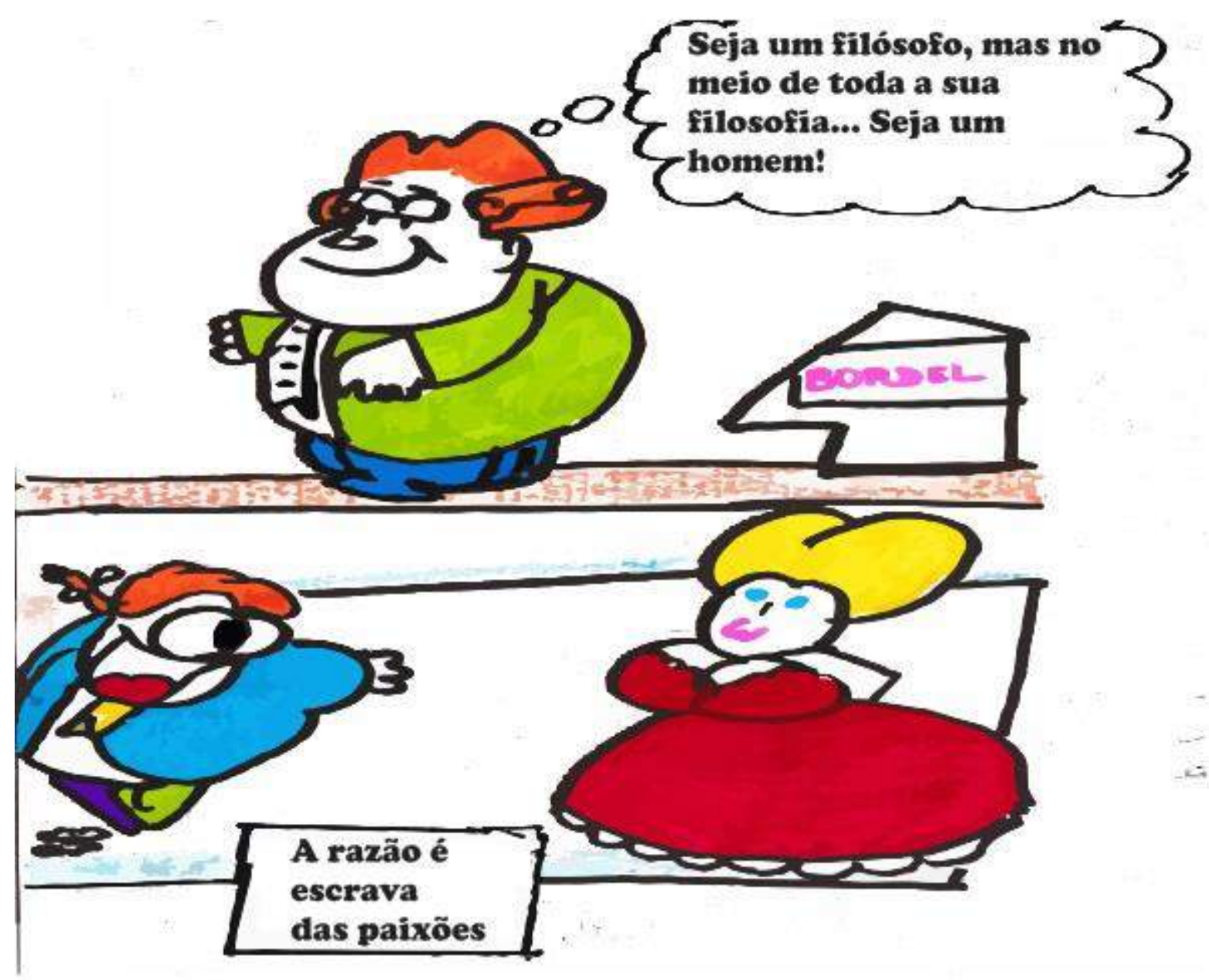

Por Eliana de Passos Silva de Oliveira

Busquem o prazer de aprender, amem a sabedoria e apaixonem-se pela ciência, mas tenham cuidado para não se castigar, não se deixem embaralhar pelas descobertas que encontrarem. Sejam humanos de tal forma que possam gozar a vida, contudo companhias agradáveis não são boas para o homem afirmar-se com seus pensamentos. Tais ações não proporcionam a gelicidade, o homem é um ser social e também ativo com várias necessidades.

É preciso então que os homens se privem de um pouco de tudo, do conhecimento pela ciência, das incertezas da filosofia, do repouso físico e espiritual, das paixões e desejos. Assim, é possível que sejam pensadores com posturais intelectuais, mas também artistas que esculpem a vida com variação de cores. 


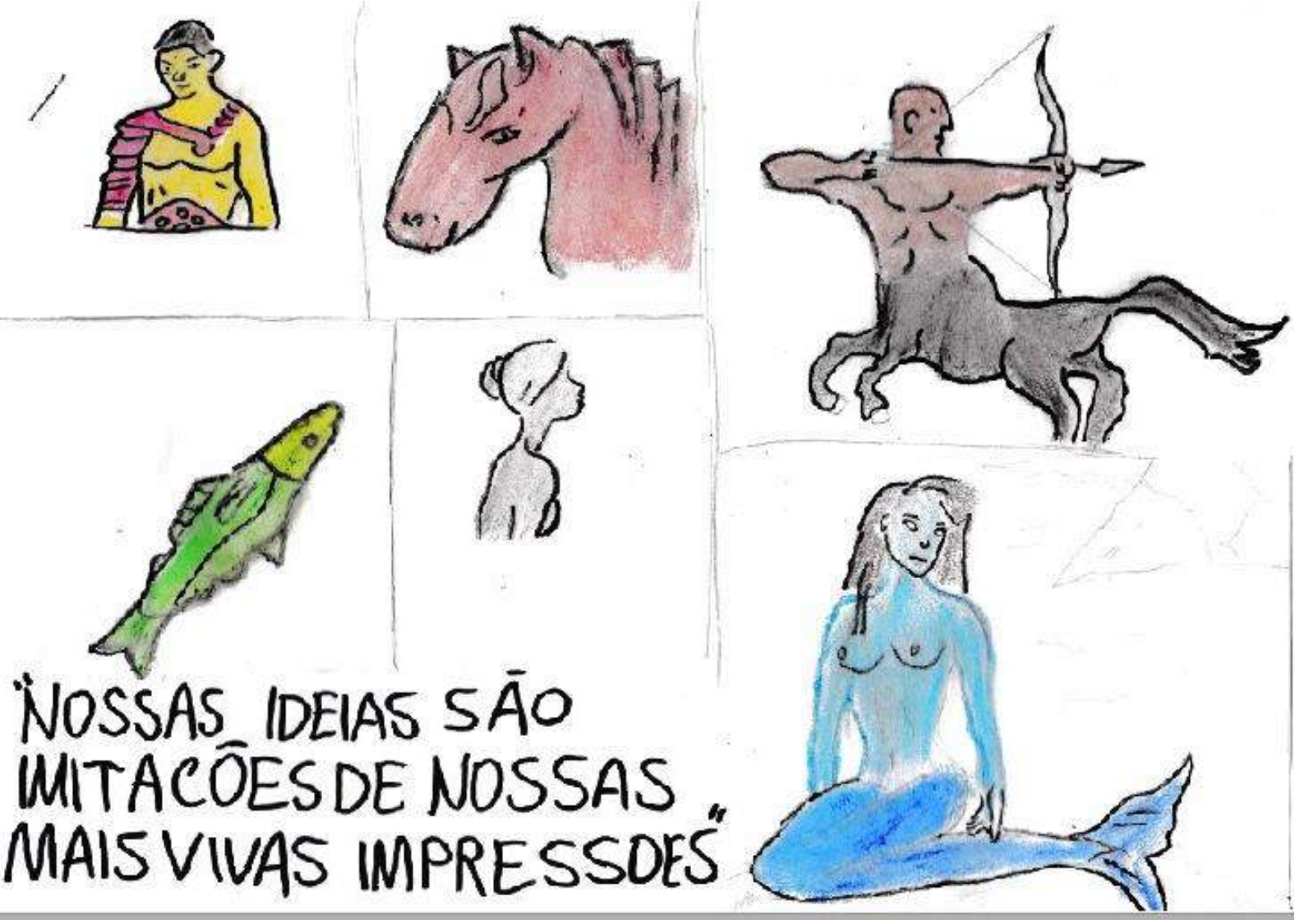

Por Joseilson P. Souza

Quando a origem do conhecimento, há filósofos que defendem que ele vem da mente ou da experiência. Para uma parte das pessoas, é comum falar dos seres inanimados como unicórnios, sereias, etc. Sem se perguntar por suas origens, na literatura clássica, bem como na cultura popular, não só unicórnios como sereias estão no imaginário. [...] A questão é como estas imagens se formam na mente e o que a questão passar do âmbito comum para o filosófico?

Para uma perspectiva que admite que imagens como, a de um cavalo alado, que vem da imaginação, não seria necessário explicar, que tais imagens têm como origem última as ideias, independente da experiência. Hume foi um dos filósofos que afirmaram que o conhecimento tem origem na experiência, seja pela observação direta da realidade, seja pelo acesso das ideias na mente, mas que também foram dadas pela experiência. Como é possível explicar a origem de seres mitológicos e inanimados, uma vez que não é possível ter experiência deles? [...] A mente que capta pelos sentidos da visão, da audição, etc., organiza as informações captadas, de modo que nem sempre é necessário recorrer a própria realidade para produzir uma informação, uma imagem, Nesse sentido que a imaginação produz algum objeto, pela imaginação ela é capaz de organizar e unir dois ou mais objetos formando uma imagem. 


\section{Locke}

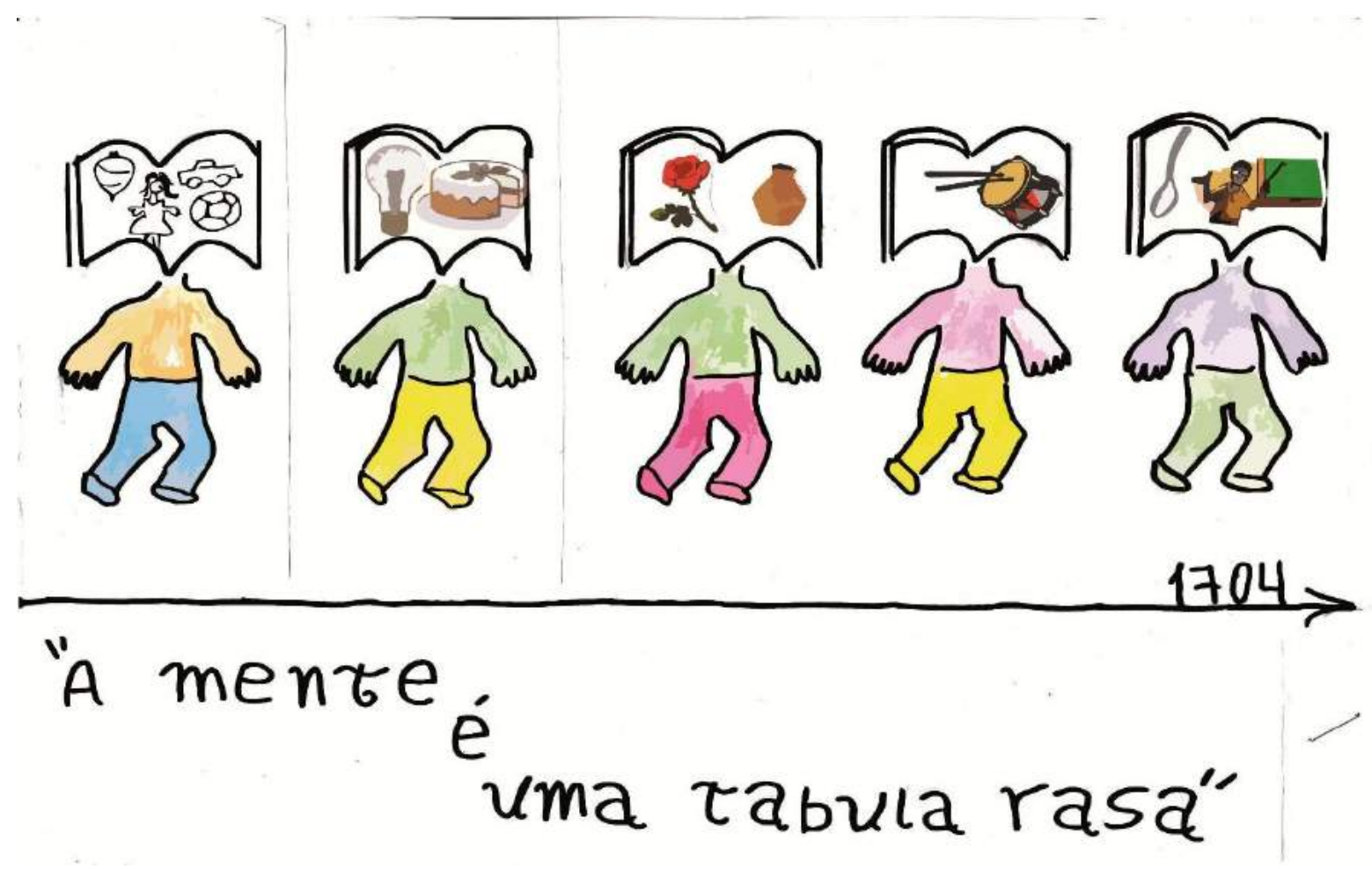

\section{Por Katússia Benedita Almeida}

Todas as pessoas nascem e vivem suas vidas tendo contato com outras pessoas, objetos, lugares, culturas, linguagens, etc. Ao passar por esse processo, adquirem conhecimentos e experiências. $\mathrm{Na}$ linguagem comum, a experiência pode ser vários significados. Para alguns, a experiência surge pelo processo de maturidade, desse modo, os mais experientes são os que mais viveram e aprenderam. Para outros, a experiência pode ser o conjunto de fatos ocorridos, mais intensos e que marcam mais os indivíduos. As experiências singulares fazem as pessoas ficarem mais preparadas para as questões da vida. $\mathrm{Na}$ filosofia, a experiência parece muitas vezes um vocabulário estranho, visto que vem da reflexão de como os indivíduos adquirem o conhecimento, como as informações de vários tipos vem parar na mente.

Para alguns filósofos, a experiência é um processo, porém, cada pessoa já nasce com as condições de conhecer, independente de uma experiência prévia. Para outros filósofos como Locke, todo conhecimento vem à mente pela experiência. Desse modo, só pelos sentidos é possível ao sujeito ter acesso ao mundo exterior. O conhecimento resulta deste processo, em que os conteúdos mentais de posso dos sujeitos, provêm daquilo que foi experenciado. Para Locke, a mente do homem é como uma folha em branco, na qual a realidade vai deixando suas marcas. 
Imagem Final, por Sanoraide Santos

O ser humano não nasce com seu caráter formado. Para ser moral e ético, é preciso que haja experiência desde a fase criança até a adulta. A educação também contribuí para a formação do homem, para que internamente ele seja instruído em uma sociedade. As vezes a ética tem um manual a ser seguido, a moral é construída dentro de nós. Cabe a qualquer ser escolher o bem ou o mal, e ter liberdade para ser livre, sem precisar do controle da religião ou da sociedade em geral. Tolerância com os credos e direito a propriedade, é o que Locke diria...

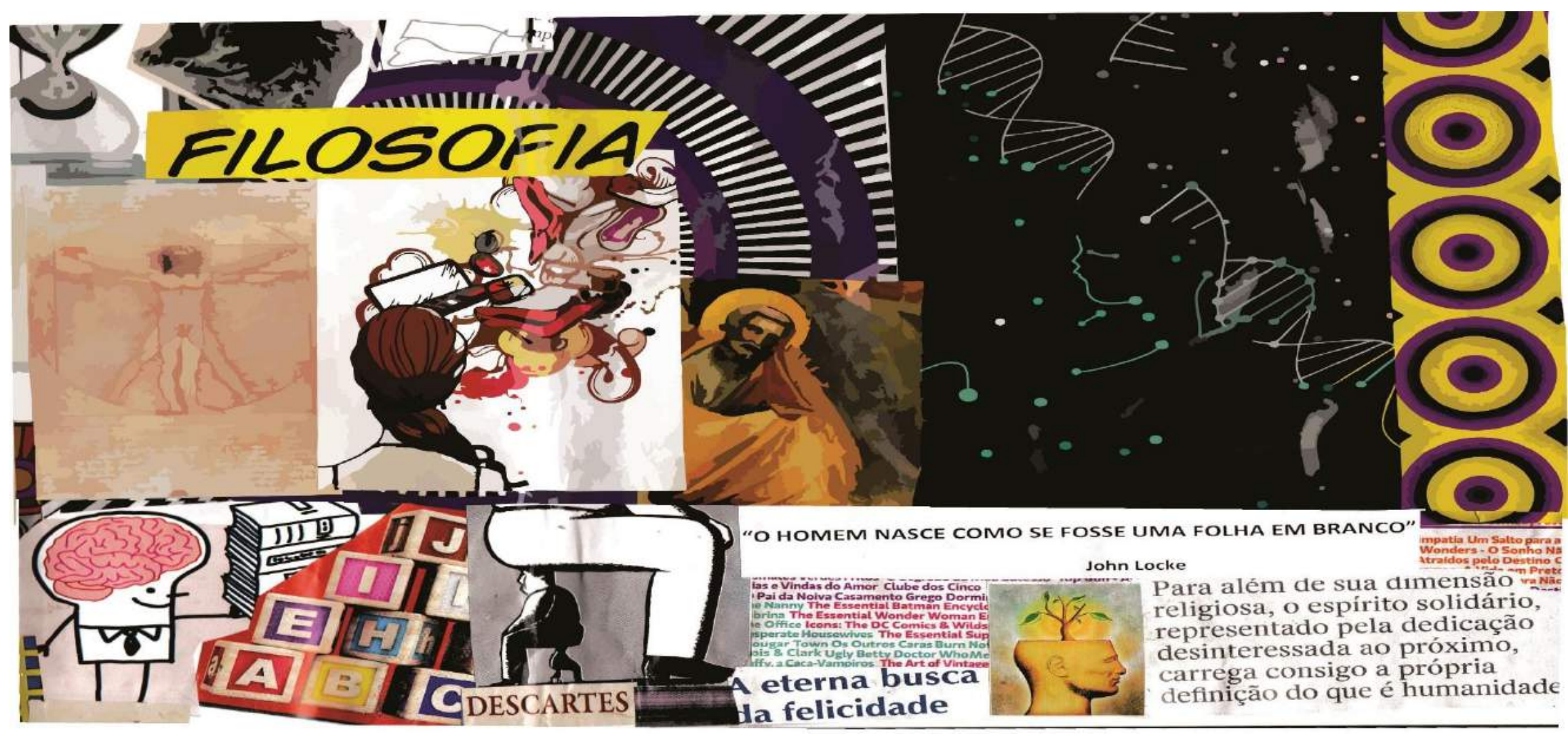

